\title{
Investigation of sediment accumulation in Nubia Lake, using RS/GIS
}

\author{
A. M. Negm \\ Department of Environmental Engineering, Egypt-Japan University of Science and Technology E-JUST, New \\ Borg El-Arab, Alexandria, Egypt (Seconded from Faculty of Engineering, Zagazig University) \\ M. A. Elsahabi \\ Civil Engineering Department, Faculty of Engineering, Aswan University, Egypt
}

\begin{abstract}
The main focus of this paper is to detect the changes in AHDL bed surface (sedimentation and erosion) in the period 2000-2012 in the active sedimentation zone of the Lake which is located in Nubia Lake (Sudanese part of AHDL). To enable this detection, the remote sensing (RS) and (Geographic Information Systems) GIS techniques are used to build the 3-D profile of the Lake portion where most of the sediment accumulate. Also, the accumulated sediment during this period is computed using the developed 3-D profile and using the cross section method as conducted by Aswan High Dam Authority (AHDA). Also, the surface areas of sedimentation and erosion are mapped and computed. Results indicated that sedimentation are dominant in years with high flood while erosion occurs when the incoming flow to the lake is low. Moreover, results indicate that the present approach overestimate the sedimentation amount by about $4 \%$ compared to the results of the method used by AHDA.
\end{abstract}

\section{INTRODUCTION}

The AHDL water capacity is affected directly by the changes in the lake's bed surface. Monitoring these changes is vital as it provides the decision maker with sufficient information to manage both the sediment removal process and storage capacity of the lake. Satellite observations data have been combined with in-situ measurements, using GIS analyst tools, to estimate and analyze changes in lakes bed surfaces, with successful applications in different parts of the world. The morphological changes related to erosion / sedimentation processes occurred in San Giuliano Lake which located in Basilicata Region (Southern Italy), in the period 1984 2004 were analyzed using RS data integrated in GIS technique (Curzio et al. 2013). Schultz (1997), detected the changes in sediment and erosion in the upper region of Lake Kemnade in the Ruhr River valley in Germany using remote sensing techniques and echo sounding data for a period of eight years. El-Gammal (2010), used Landsat TM images and GIS technique in change detection of water levels in AHDL from 1972 to 2008 and also, used these images integrated with the available field data about sedimentation in AHDL to estimate the volume and place of sediment in some portions of this lake. ElSammany \& El-Moustafa (2011), used GIS tool to propose a method for calculating the changes in AHDL bed from year 1953 to 2004. The method was depending on the processing of the field measurements (bathymetric data) only using GIS tools, such as geo-spatial analysis and 3D analyst tools in order to form and analyze the Digital Elevation Models (DEMs) for the lake.

The main objectives of the present paper are to:

i.Detect the changes in AHDL active sedimentation portion bed surface (sediment / erosion) and their amounts from year 2000 to 2012 using GIS / RS techniques.

ii.Detect the effect of inflow quantity (flood/drought) on sediment and erosion amounts.

\section{STUDY AREA AND DATA COLLECTION}

\subsection{Selection of the study area}

The main two parts of AHDL include the Egyptian part with a length of about $350 \mathrm{Km}$ and called Nasser Lake and Sudanese part (LakeNubia) with a length of $150 \mathrm{Km}$. The present study focuses on the Sudanese part which is the most active sedimentation portion of the AHDL In addition, from the studies and observations don.e by the repetitive field survey missions, which successfully carried out through the joined efforts of the Aswan High Dam Authority (AHDA) and the Nile Research Institute (NRI), it is obvious that the cross 
sections have been enlarged and the water velocity have been decreased in this reach. So, this portion of the lake represents the area with most intensive sediment deposition. Moreover, more than $50 \%$ of the sediment exists in this portion. NRI (2012) estimated that about $(50 \%-70 \%)$ of the total amount of sediment in AHDL were deposited in this portion of the lake, although this portion represents only about $5.96 \%$ of the total area of AHDL, MWRI (2012). This portion of AHDL called (the active sedimentation portion). The study area of the present research extends between latitudes $21^{\circ} 44^{\prime} 30^{\prime \prime} \mathrm{N}$ and $22^{\circ} 00^{\prime} 00^{\prime \prime} \mathrm{N}$ (upstream AHD). It contains 6 cross sections $(28,27,26,25,24$ and 22) from the South to the North respectively as indicated in Figure 1.

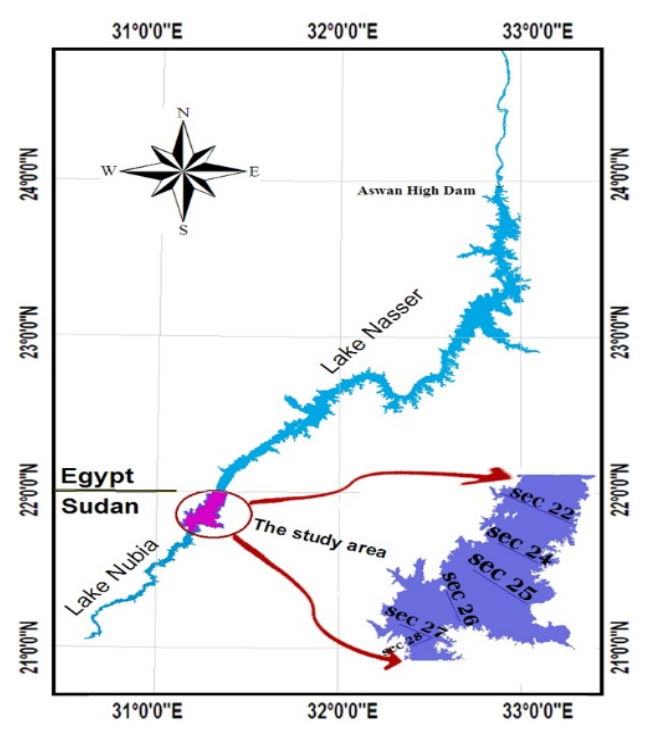

Figure 1. Study area (active sedimentation zone of Nubia Lake).

\subsection{In-situ data}

\subsubsection{Hydrographic survey data}

The hydrographic survey data of AHDL were conducted by using the eco-sounder via field trips provided by (AHDA and NRI). The lake geometry presented by Easting, Northing, and Elevation (E, N, and Z) was used for hydrographic survey data of years 2000, 2004, 2006, 2008, 2010 and 2012 for the study area are used, NRI (2012). All the field trips used the multi-beam echo sounding system. This system was integrated with real time positioning of GPS (the position was corrected on the spot by the integrated Omni star system into the GPS unit). The corrected position was synchronized with depth from the echo-sounder (data processing). In the end, the system was capable of collecting huge data set (the total points after processing are about 133 thousand for each trip) for flow depth ranged from 0.3 to $220 \mathrm{~m}$ with accuracy about $\pm 0.1 \%$ of water depth, which considered as an indicator for the data uncertainties. The water levels upstream AHD which recorded by AHDA gauge stations in the different dates of the year, MALR (2010) are collected to help in detecting the water surface levels at the dates of acquiring the satellite images.

\subsubsection{Inflow data}

The total amounts of discharge (inflow) which arrive Aswan (enter Egypt) for the last twenty years, which recorded by AHDA according to Dongola gauge station, MWRI (2012) are used to detect the effect of this discharge on the lake's bed changes.

\subsubsection{Lake bed soil samples data}

The Lake bed material samples were collected via the field trips using the bed material sampler at locations of the cross-sections shown in Figure 1. Then the grain size distribution of these samples was identified in AHDLA and NRI laboratories in order to, investigating the nature of the deposited particles and classifying them according to their geometrical characteristics. The collected samples of the year 2012 are used in the current study. Though studying of these samples, it is noticed that; sand - medium grained size particles- and (silt \& clay) - fine to very fine grained size particles - are the major components of these samples. Meanwhile; these samples do not contain any gravel - coarse grained size particles - at all.

\subsection{Satellite images (remote sensing data)}

Three Landsat ETM + images $($ Path $/$ Row $=175 / 045)$ are used in this research. The three images were acquired at different dates (September 2000, March 2006 and March 2009) from the GLCF website in GeoTIFF (systematic correction) products, GLCF (2014). For thus, it is free of geometric, radiometric and noise errors. The acquired images were used to extract the lake boundaries.

\section{METHODOLOGY}

To achieve the objectives of the present paper, the tasks presented in Figure 2 are conducted. The major tasks include: water surface area extraction, prediction of the 3D bed surfaces, change detection process, establishing maps of changes and producing of the sediment particles distribution maps. These tasks are breifly explained in the following subsections: 


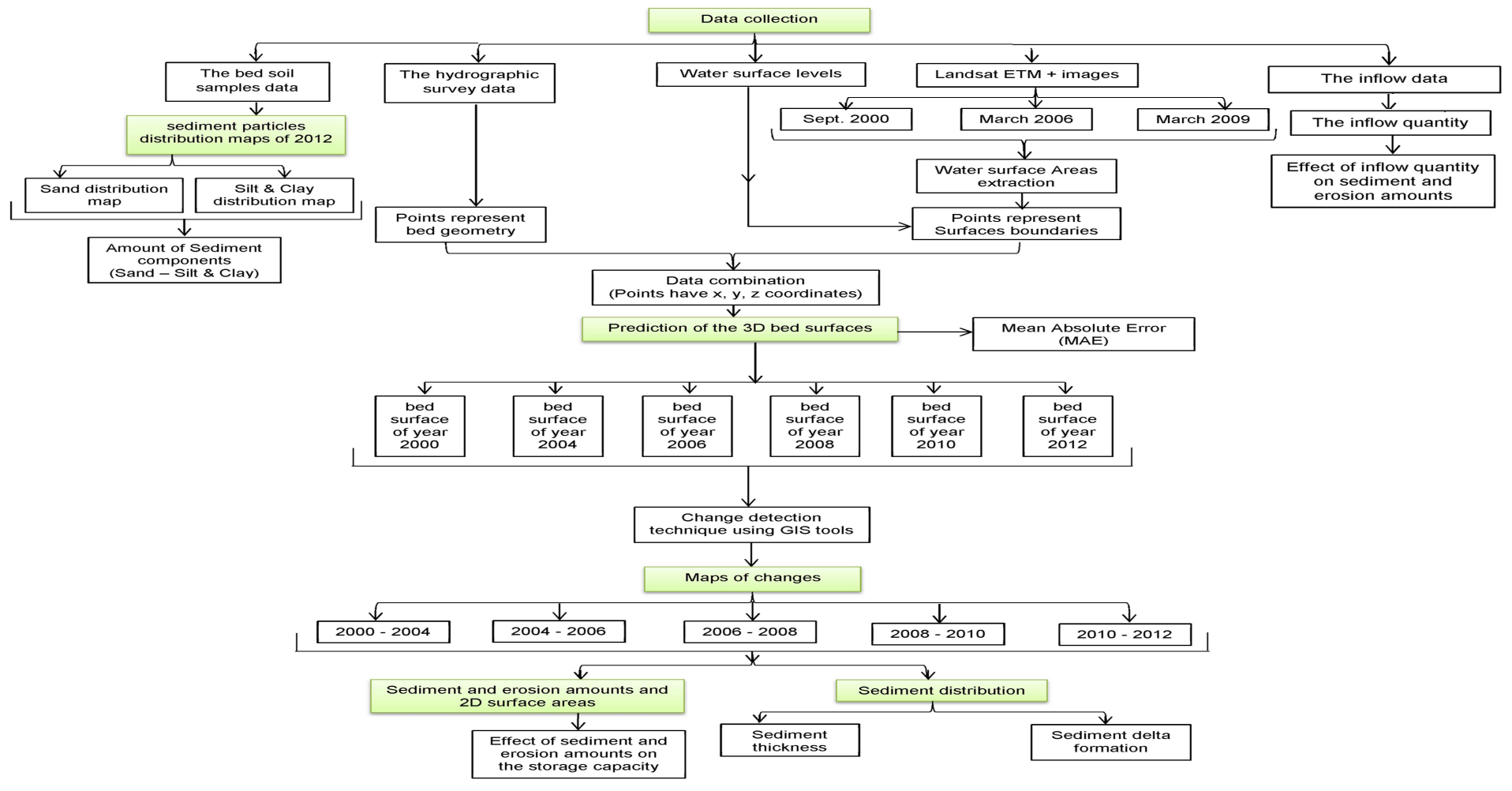

Figure 2. Flowchart of the procedures adopted in this study to investigate erosion and sedimentation patterns of the study area

\subsection{Water surface areas extraction}

The water boundaries delineation from Landsat satellite images, using ArcGIS software, was performed by six techniques:

- By image classification techniques (supervised and unsupervised techniques), (Ebaid \& Ismail 2010, Lillesand et al. 2004). Three satellite images were used. The first was shot in September 2000 where the water level in the lake was $(178 \mathrm{~m})$ amsl. The second was shot in March 2006 where the water level was $(173 \mathrm{~m})$ while the third was shot in March 2009 where the water level was $(176.60 \mathrm{~m})$.

- Normalized Difference Water Index (NDWI), (Muala et al. 2014) as given by the following equation:

$$
N D W I=\frac{(\text { Green }-N I R)}{(\text { Green }+N I R)}
$$

- Modified Normalized Difference Water Index (MNDWI), (Muala et al. 2014) as given below:

$$
M N D W I=\frac{(\text { Green }- \text { MIR })}{(\text { Green }+ \text { MIR })}
$$

- Automated Water Extraction Index (AWEI), (Feyisa et al. 2014)

$$
\text { AWEI }=4 \times(\text { Green }-M I R)-(0.25 \times N I R+2.75 \times \text { SWIR })
$$

- Normalized Difference Moisture Index (NDMI), Wilson \& Sader (2002) as below:

$$
N D M I=\frac{(N I R-M I R)}{(N I R+M I R)}
$$

The positive values of the computed water indices by equations from 1 to 4 represent water bodies and negative values represent land areas.

Green, NIR, MIR and SWIR represent green, near-infrared, middle-infrared and shortwaveinfrared bands of the Landsat ETM+ images respectively.

The applied procedures for extraction of water boundaries in this study (using unsupervised Image classification technique) is shown in Figure 3 and is explained as below:

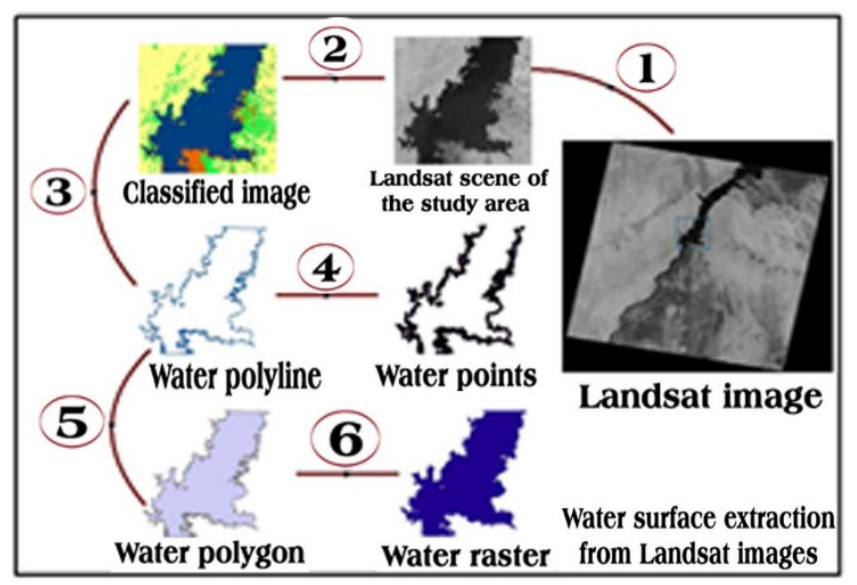

Figure 3. Extraction of water boundaries from Landsat images. 
1)Detecting the Landsat scene of the study area by making a clip from the original image.

2) Making unsupervised classification, then converting the final classified image (contain 4 classes) into features (vector layers).

3) Separating the water feature from the other features as a polyline.

4) Converting the polyline boundaries into water points layer, which have $(\mathrm{x}, \mathrm{y})$ coordinates and $\mathrm{z}$ from the water levels recorded by AHDA which synchronized with the acquired dates of the satellite images.

5)Converting the water polyline layer into polygon layer.

6) The last step is the conversion process from the polygon layer to raster water scene (water raster) to help in the interpolation method (predicting the 3D bed surface).

The derived water areas were overlaid with the reference water area to display the degree of misclassification error in water surfaces extraction. Finally, the overall accuracy, Story \& Congalton (1986), is computed to support the accuracy assessment analysis.

The extracted lake boundaries as obtained from the satellite images, were used to form the shape of surface and also, to form a group of scatter points $(\mathrm{x}, \mathrm{y}, \mathrm{z})$ using the WGS84, UTM Z36N as a defined projected coordinate system. These points were used, combined together with the hydrographic survey points in the generation of the 3D bed surfaces of the study area for all available years $(2000,2004,2006$, 2008, 2010, and 2012).

\subsection{Prediction of the $3 D$ bed surfaces}

To predict the original 3D bed surfaces of the lake from the year 2000 to the year 2012, the available hydrographic survey data combined with the points that represent the water surface areas which derived from Landsat satellite images, were used in the interpolation process. In addition the water surface, that represents the highest surface for all predicted bed surfaces, was of the 2000 Landsat image. The interpolation process was performed with the Radial Base functions (RBF) method, ESRI (2008).

The Mean Absolute Error (MAE) was used to assess the accuracy of the interpolation method. For accurate interpolation process, the MAE should be near zero.

\subsection{Change detection Process}

This process was done by using the change detection technique which is a digital overlaying technique that depends on detecting the changes in the lake's bed levels via overlaying every two sequent predicted bed surface using (cut / fill) tool in ArcGIS Software.

\subsection{Establishing maps of changes}

The maps of changes which represent the changes (sediment / erosion) zones were generated to quantify the changes amounts in the study area through the period from the year 2000 to the year 2012 .

\subsection{Producing of the sediment particles distribution maps}

The sediment particles distribution maps generated from the interpolation process of the bed soil samples data of the year 2012; represent the distribution of sand and (silt \& clay) through the bed of the study area.

\section{RESULTS}

\subsection{Extraction of water surface areas}

The results indicate that the unsupervised classification technique performed significantly better compared with other techniques for surface water extraction. The overall accuracy of the unsupervised technique is about $98.50 \%$. The visual comparison shows that the boundaries of the extracted water surface match the actual boundaries of the water in the reference image very closely. Therefore, this technique was used to delineate the water surface areas in this study from all available Landsat images. For more information, readers might consult, (Elsahabi et al. 2016) if they are interested in more information.

\subsection{Interpolation process}

Prediction of the 3D bed surfaces necessates the use of the Radial Base functions (RBF) method for interpolation to produce accurate results for gently varying surfaces such as elevations, ESRI (2008). 

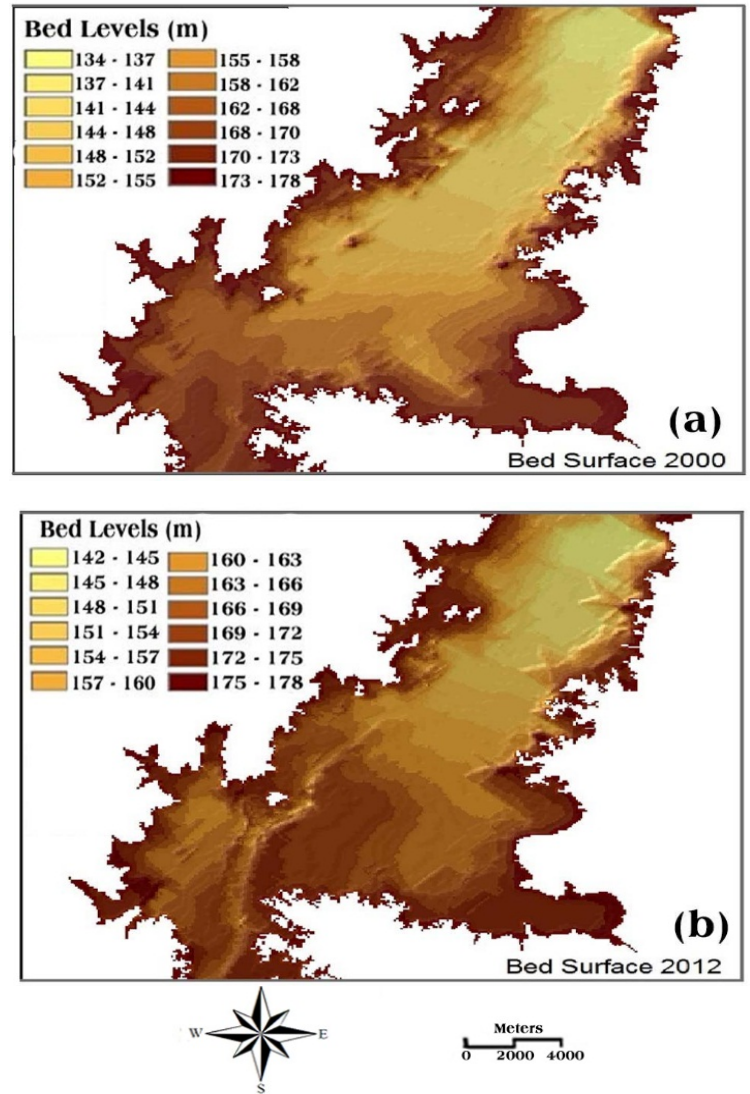

Figure 4. Sample results of the predicted bed surfaces for (a) the years 2000 and (b) the year 2012 .

The mean absolute error, MAE, was used too assess the accuracy of the used RBF method. The vaules of MAE were found to be near to zero for all studied years. The $\mathrm{R}^{2}$ between the measured and the interpolated values is found to be 0.998 while the MAE for the year 2000 equals $0.02473 \mathrm{~m}$ indicating high accuracy of interpolation process.

The 3D bed surfaces are predicted for the years 2000, 2004, 2006, 2008, 2010 and 2012. Sample results are presented in Figures $4 \mathrm{a}$ and $4 \mathrm{~b}$ for the year 2000 and the year 2012 .
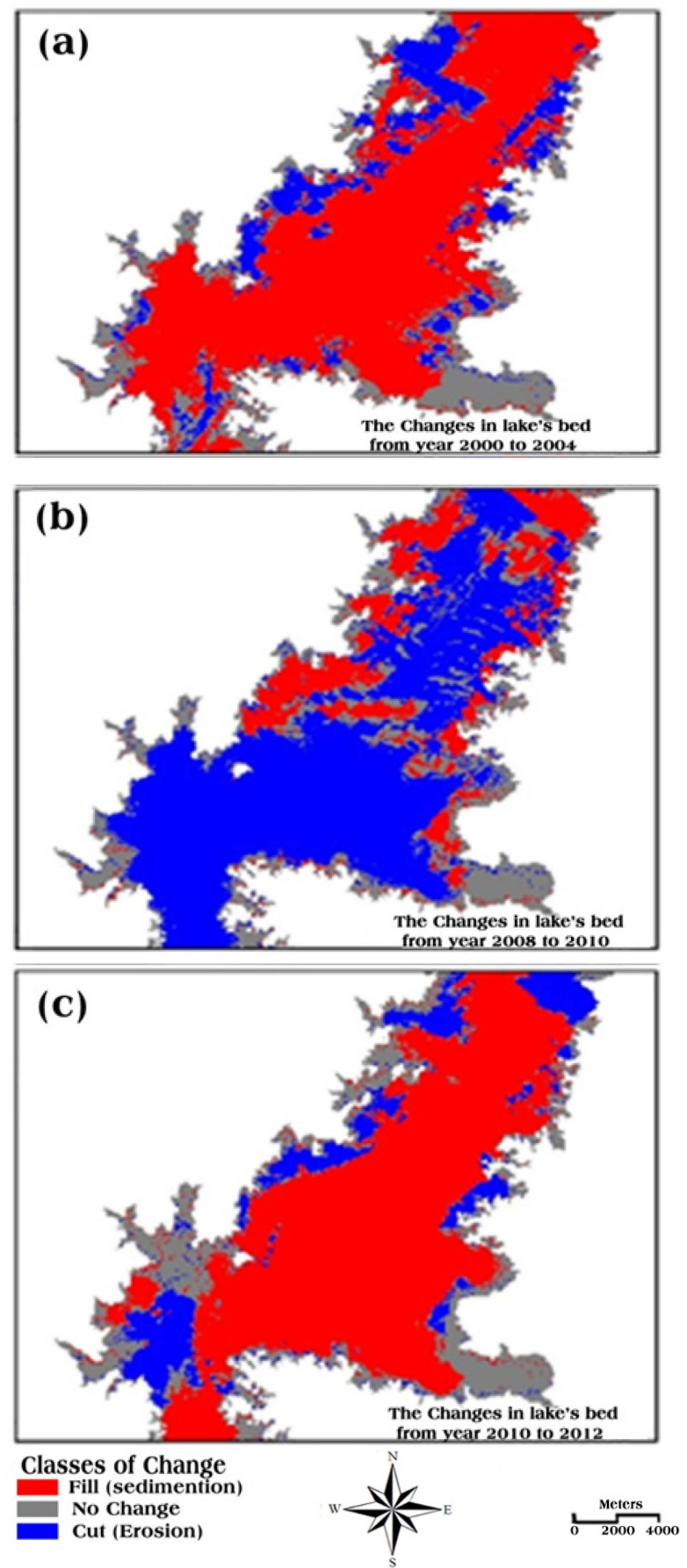

Figure 5. Sample for maps of changes for the years (a) 20002004, (b) 2008-2010 and (c) 2010-2012.

\subsection{Maps of changes}

The changes in bed levels between every two sequent predicted bed surfaces were generalized by three broad change categories:

- No change: the levels that have the same values in the old and new bed surface.

- Sedimentation: the old bed surface levels that were increased in the new bed surface.

- Erosion: the old bed surface levels that were decreased in the new bed surface.

Maps of changes for the years 2000-2004, 20042006, 2006-2008, 2008-2010 and 2010-2012 are produced. Samples for the years 2000-2004, 20082010 and 2010-2012 are presented in Figure 5. 


\subsection{Sedimentation distribution and delta formation}

Figure 6 shows the sedimentation distribution and delta formation map which was produced from subtracting process between the bed surfaces of years 2000 and 2012. It is obvious from this figure that there was a variation in sedimentation thickness from the year 2000 to the year 2012 along the study area, the maximum depth of sediments was estimated to be about $28 \mathrm{~m}$.

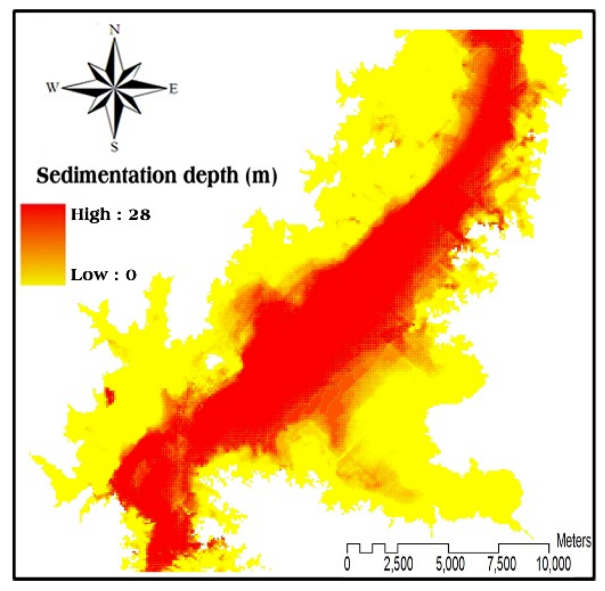

Figure 6. Sedimentation distribution and delta formation map for the period (2000 to 2012).

Figure 7 illustrates the 3D model of the sedimentation distribution and delta formation, which indicates that the submerged delta of sediment was formed in the middle part of the study area. Moreover, it obviates the variations in sedimentation depths through the studied time period.

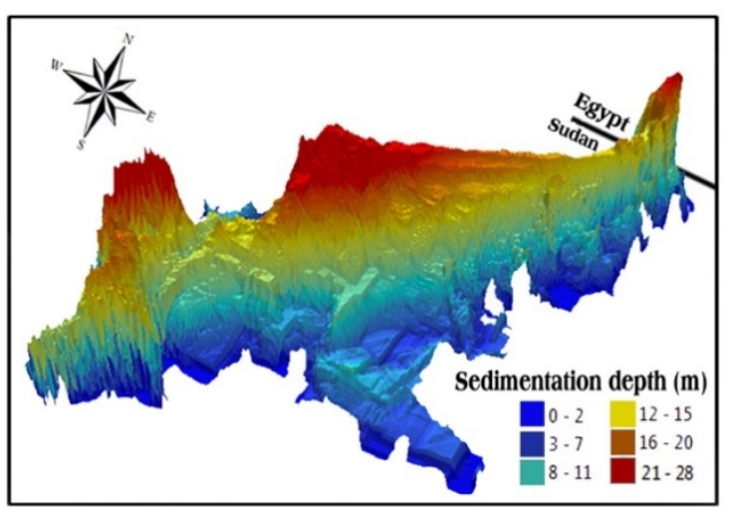

Figure 7. The 3D model of the sedimentation distribution and delta formation from the year 2000 to the year 2012 .

\subsection{The lake bed soil particles distributions maps}

Figures ( $8 \mathrm{a}$ and $8 \mathrm{~b}$ ) show the lake bed soil particles distributions maps of the year 2012 that represent the sediment components map. These maps represent sand distribution map and (silt \& clay) distribution map respectively which were generated from the interpolation process of the collected soil samples data using ArcGIS software.
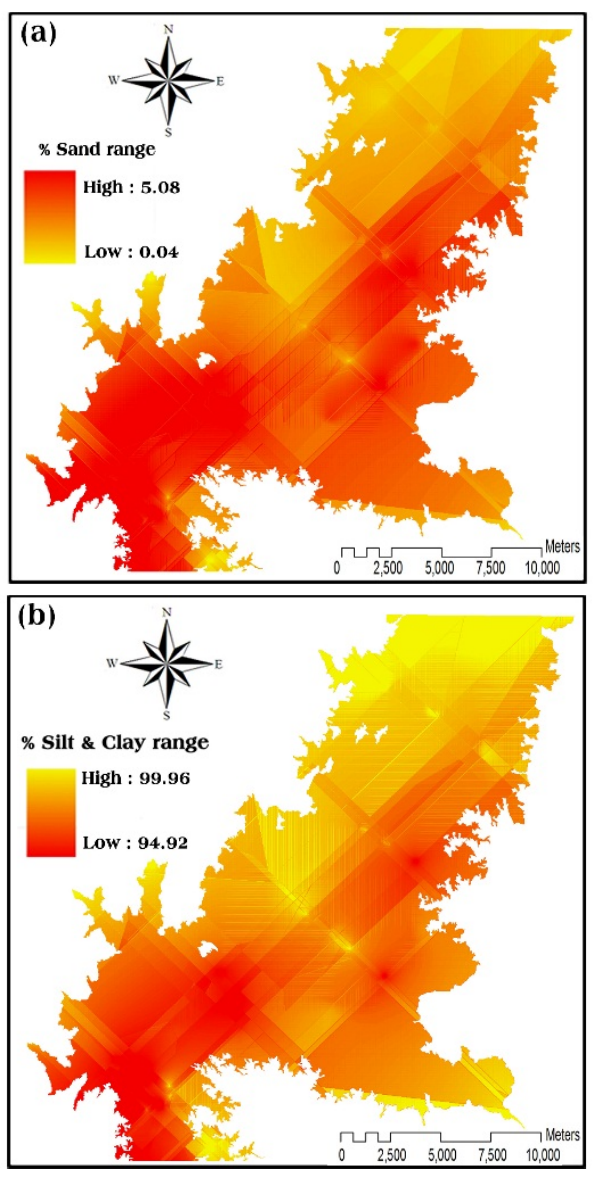

Figure 8. The lake bed soil particles distributions maps of the year 2012: (a) sand distribution map; (b) silt \& clay distribution map

According to these maps, it can be clearly noticed that, silt \& clay particles (fine soil particles) are distributed with high amount all over the study area. On contrast, the sand particles are distributed with a low amount, which indicates that (silt \& clay) are the predominant components of the deposited sediment particles.

\section{DISCUSSIONS}

\subsection{Sediment and erosion changes}

Figure 9 and Figure 10 show the change in sediment and erosion amounts respectively from the year 2000 to 2012, as estimated by using the statistics of the change categories (classes) in the maps of changes. It is observed from Figures 9 and 10 that there was an increase in the amount of sediment from years 2000 - 2004, 2006 - 2008 and 2010 - 2012 accompanied with a decrease in the amount of erosion in the same periods.

Otherwise, there was a decrease in the amount of sediment from the year 2008 to to the year 2010 accompanied with an increase in the amount of erosion in the same period. From the year 2004 to 2006, the amount of sediment is nearly equal to the amount of erosion. 


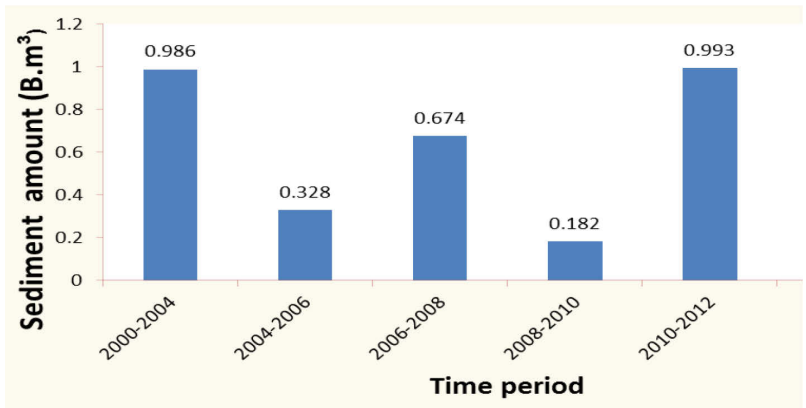

Figure 9. Sediment amount in the study area.

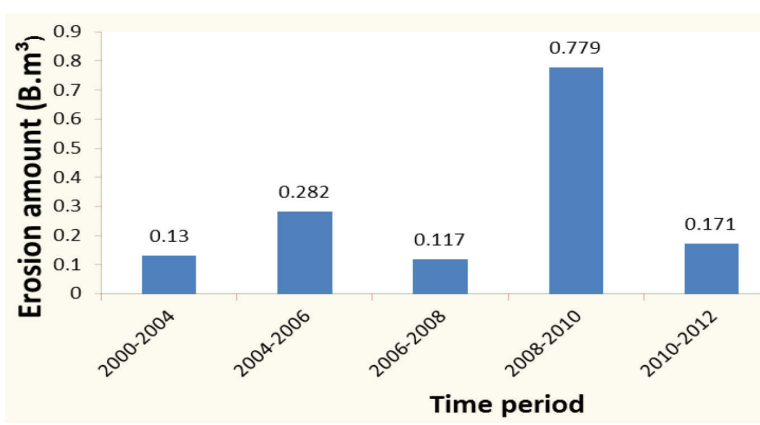

Figure 10. Erosion amounts in the study area.

Table 1 shows the change in sediment and erosion 2D surface areas respectively from the year 2000 to the year 2012, it is obvious from this Table that the values of the $2 \mathrm{D}$ areas of sediment and erosion were approximately proportional to the amounts of sediment and erosion, as the amount of erosion increase lead to increase in its 2D area and vice versa, and the same manner for sediment.

\subsection{Effect of inflow quantity on sediment and erosion amounts}

The results presented in Figures (9 and 10) can be explained in terms of inflow quantity. Table 2 shows the difference in the annual inflow quantity (discharge) in the study area, which recorded at Aswan at the end of July, MWRI (2012).

Table 1. 2D surface area of Sedimentation and Erosion from the year 2000 to 2012

\begin{tabular}{lcc}
\hline $\begin{array}{l}\text { Time } \\
\text { period }\end{array}$ & $\begin{array}{c}\text { 2D area of sediment } \\
\left(\mathrm{Km}^{2}\right)\end{array}$ & $\begin{array}{c}\text { 2D area of erosion } \\
\left(\mathrm{Km}^{2}\right)\end{array}$ \\
\hline $2000-2004$ & 227.45 & 47.06 \\
$2004-2006$ & 145.70 & 91.38 \\
$2006-2008$ & 216.05 & 48.84 \\
$2008-2010$ & 59.93 & 205.81 \\
$2010-2012$ & 222.28 & 50.19 \\
\hline
\end{tabular}

Table 2 . The quantity of inflow from $(2000-2012)$

\begin{tabular}{lcc}
\hline Year & Inflow $\left(\mathrm{Bm}^{3}\right)$ & Average $\left(\mathrm{Bm}^{3}\right)$ \\
\hline $2000-2001$ & 69512 & \\
$2001-2002$ & 70878 & \multirow{2}{*}{59678} \\
$2002-2003$ & 41794 & \\
$2003-2004$ & 56528 & \\
\hline $2004-2005$ & 47287 & \multirow{2}{*}{50403} \\
$2005-2006$ & 53518 & \\
\hline $2006-2007$ & 80420 & \multirow{2}{*}{78170} \\
$2007-2008$ & 75920 & \\
\hline $2008-2009$ & 55130 & \multirow{2}{*}{48635} \\
$2009-2010$ & 42139 & \multirow{2}{*}{56700} \\
\hline $2010-2011$ & 63314 & \\
$2011-2012$ & 50085 &
\end{tabular}

By comparing this Table with Figure 10, it is observed that the amounts of erosion affected directly by the amounts of inflow, as the decrease in the inflow quantity lead to increase in the amount of erosion and vice versa, that explains the change in the amount of erosion from the year 2000 to the year 2012.

From Table 2 and Figure 9, it is clear that there is an increase in sediment amount between years $2000-2004,2006-2008$ and $2010-2012$ due to the increase in the inflow amount. While, there was a decrease in sediment amount between $2008-2010$ due to the decrease in the inflow quantity. In spite of this, a direct relation between the sediment amount and the incoming flow to the lake couldn't be detected. As, sediment amount depends not only on the quantity of inflow but also, some other parameters such as: the particles size of sediment, the inflow velocities and shape \& size of the lake's cross sections which are perpendicular to the incoming flow to the lake.

\subsection{Effect of sediment and erosion amounts on the water capacity of the study area}

Table 3 illustrates the effect of sediment and erosion amount on the water capacity from the year 2000 to 2012. This table indicates that there is a decrease in the water capacity from the year 2000 to 2008 and from the year 2010 to 2012 due to sediment accumulation (the amount of sediment is higher than the amount of erosion). Otherwise, there is an increase in the water capacity by $0.597 \mathrm{Bm} 3$ from the year 2008 to 2010, because of the higher amount of erosion than the amount of sediment.

The previous results showed that by increasing sediment amount than erosion amount, the water capacity decrease and vice versa. 


\begin{tabular}{llllll}
\hline Year & Time period & $\begin{array}{l}\text { Water } \\
\text { capacity } \\
\left(\mathrm{Bm}^{3}\right)\end{array}$ & $\begin{array}{l}\text { Difference between } \\
\text { sediment and erosion } \\
=\text { Total change } \\
\text { amount }\left(\mathrm{Bm}^{3}\right)\end{array}$ & Case & $\begin{array}{l}\text { Type of total } \\
\text { change }\end{array}$ \\
\hline 2000 & $2000-2004$ & 4.964 & 0.856 & Decrease in water capacity & Sedimentation \\
2004 & $2004-2006$ & 4.108 & 0.046 & Decrease in water capacity & Sedimentation \\
2006 & $2006-2008$ & 4.062 & 0.557 & Decrease in water capacity & Sedimentation \\
2008 & $2008-2010$ & 3.505 & -0.597 & Increase in water capacity & Erosion \\
2010 & $2010-2012$ & 4.102 & 0.822 & Decrease in water capacity & Sedimentation \\
\hline
\end{tabular}

\subsection{Comparisons}

Table 4 illustrates that the total amount of sediment from the year 2000 to 2012 was about 1.684 billion $\mathrm{m}^{3}$. This amount is the Sum of total change amount from table 3 . This value is very close to the estimated sediment amount by AHDA (the traditional method) which has a value equal to 1.617 billion $\mathrm{m}^{3}$, NRI (2012). This means that the present approach, which based on building $3 \mathrm{D}$ profiles for the study area, overestimate the sedimentation amount by about 4\% from the year 2000 to 2012 compared to the results of the method used by AHDA. This low percent indicate the high performance of AHDA and NRI in measuring and collecting the sediment data.

Table 4. Comparison between the present results and those of the traditional methods for sediment amount estimation in the study area from the year 2000 to the year 2012 .

\begin{tabular}{ccc}
\hline Time period & $\begin{array}{c}\text { Amount of sed- } \\
\text { iment by GIS/RS } \\
\text { method }\left(\mathrm{Bm}^{3}\right)\end{array}$ & $\begin{array}{c}\text { Amount of sed- } \\
\text { iment by AHDA } \\
\text { method }\left(\mathrm{Bm}^{3}\right)\end{array}$ \\
\hline $2000-2012$ & 1.684 & 1.617 \\
\hline
\end{tabular}

\subsection{Amounts of sediment components}

Table 5 obviates that; the total amount of the deposited sand from the year 2012 was about 0.03 billion $\mathrm{m}^{3}$. Moreover, the amount of the deposited (silt \& clay) was about 1.654 billion $\mathrm{m}^{3}$.

These amounts were computed from the statistical analysis of both the sedimentation distribution map shown in Figure 6 -and the lake bed soil particles distributions maps shown in Figure 8. These computations were performed by using the Raster calculation tool in ArcGIS software. According to these amounts it can be noticed that, the predominant sediment particles in the study area are silt \& clay which represent about $98.2 \%$ of the total amount of sediment particles.
Table 5. The amounts of sediment components materials in the study area from the year 2000 to 2012 .

\begin{tabular}{cccc}
\hline Time period & $\begin{array}{c}\text { Amount } \\
\text { of sand } \\
\left(\mathrm{Bm}^{3}\right)\end{array}$ & $\begin{array}{c}\text { Amount of } \\
\text { silt \& clay } \\
\left(\mathrm{Bm}^{3}\right)\end{array}$ & $\begin{array}{c}\text { Total amount } \\
\text { of sediments } \\
\left(\mathrm{Bm}^{3}\right)\end{array}$ \\
\hline $2000-2012$ & 0.03 & 1.654 & 1.684 \\
\hline
\end{tabular}

\section{CONCLUSION}

This paper presents and discusses the results of detecting the changes in the bed surface (sediment / erosion) of the active sedimentation Portion of Aswan High Dam Lake, based on using RS/GIS techniques. The results indicated that sedimentation are dominant in years with high flood while erosion occurs when the incoming flow to the lake is low. Moreover, results indicated that the present approach, which based on building 3D profiles for the lake, overestimate the sedimentation amount by about $4 \%$ from the year 2000 to 2012 compared to the results of the method used by AHDA, based on the complementary cross sections.

\section{ACKNOWLEDGMENTS}

Aswan University, Egypt-Japan University of Science and Technology (E-JUST), Aswan High Dam Authority (AHDA) and the General Authority for AHDL Development are hereby acknowledged for providing the facilities utilized during this research work.

\section{REFERENCES}

Curzio, S.L.; Russ, F. \& Caporaso, M. 2013. Application of remote sensing and GIS analysis to detect morphological changes in an artificial lake. International Journal of Re- 
mote Sensing \& Geoscience (IJRSG), Vol. 2, Issue 4, ISSN No: 2319-3484.

Ebaid, H.M.I. \& Ismail, S. S. 2010. Lake Nasser evaporation Reduction Study. Journal of advanced research, Vol.1: 315322.

El-Gammal, E.A. 2010. Assessment Lake Nasser Egypt within the climatic change. Journal of American Science, 6: 305312.

Elsahabi, M. A.; Negm, A. A. \& ALi, K. A. 2016. Performances Evaluation of Surface Water Areas Extraction Techniques Using LANDSAT ETM+ Data: Case Study of Lake Nubia, Sudan. International Conference of Engineering Sciences \&applications, ICESA 2016, Aswan, Egypt: 169-174.

El-Sammany, M. S. \& El-Moustafa, A. M. 2011. Adaptation of Surface Water Modeling System for Sediment Transport Investigations in Lake Nasser. Journal of Nile Basin Water Science and Engineering, Vol. 4, Issue 1: 71-85.

ESRI 2008: Environmental Systems Research Institute, Help topics of ArcGIS version 9.3 Desktop. Developer center of geographic information systems (GIS) software, Redlands, California.

Feyisa, G.L.; Meilby, H.; Fensholt, R. \& Proud, S.R. 2014. Automated water extraction index: A new technique for surface water mapping using Landsat imagery. Remote Sensing of Environment, 140: 23-35.

GLCF 2014: The Global Land Cover Facility, provides earth science data and products. Available from: http://glcfapp.glcf.umd.edu/data/landsat/, last accessed: May 09, 2014.

Lillesand, T.M.; Kiefer, R.W. \& Chipman, J.W. 2004. Remote sensing and image interpretation. 5th edition, (New York: John Wiley \& Sons).

MALR 2010: The Ministry of Agriculture and Land Reclamation, Egypt, the General Authority for AHDL Development, AHDL levels (1978 to 2010).

Muala, E.; Mohamed, Y.A.; Duan, Z. \& Zaag, P. 2014. Estimation of reservoir discharges from Lake Nasser and Roseires Reservoir in the Nile Basin using satellite altimetry and imagery data. Remote Sens., 6: 7522-7545.

MWRI 2012: The Ministry of Water Resources and Irrigation, Egypt, Nile Water Sector. Annual report (2011-2012).

NRI 2012: Nile Research Institute. Annual report of Sedimentation in Lake Nubia -Wadi Halfa Field trips- (1973-2012). National water Research Center, Cairo, Egypt.

Schultz, G.A. 1997. Use of remote sensing data in a GIS environment for water resources management. Remote Sensing and Geographic Information Systems for Design and Operation of Water Resources Systems (Proceedings of Rabat Symposium S3, April 1997). IAHS Publ. no. 242.

Story, M. \& Congalton, R.G. 1986. Accuracy assessment: A user's perspective. Photogrammetric Engineering \& Remote Sensing, Vol. 52, No.3: 397-399.

Wilson, E.H. \& Sader, S.A. 2002. Detection of forest harvest type using multiple dates of Landsat TM imagery. Remote Sensing of Environment, 80: 385-396. 